\title{
Acessibilidade nas escolas como uma questão de direitos humanos ${ }^{1}$
}

\author{
Acessibility to school buildings as a human right issue
}

Acessibilidad em las escuelas como uma cuestion de derechos humanos

* Daniel Mendes da Silva Filho

Professor mestre das Secretarias Municipais de Educação de Corumbá e Ladário (MS), Corumbá, Mato

Grosso do Sul, Brasil.

mendes2filho@hotmail.com

** Mônica de Carvalho Magalhães Kassar

Professora doutora da Universidade Federal de Mato Grosso do Sul, Corumbá, Mato Grosso do Sul, Brasil. monica.kassar@gmail.com

Recebido: 02 de outubro de 2017

Aprovado: 31 de agosto de 2018

\section{RESUMO}

A presença de alunos com deficiências e com dificuldades de locomoção nas escolas tem impulsionado diversas mudanças, dentre elas, as relativas à organização dos espaços. Este artigo tem como objetivo analisar a acessibilidade arquitetônica em escolas públicas, sob a perspectiva do cumprimento de diretos humanos fundamentais, como o reconhecimento como pessoa, o recebimento de instrução/educação, a liberdade de locomoção e a segurança pessoal, entre outros. Para o desenvolvimento deste estudo, inicialmente, realizou-se um levantamento documental, que levou ao conhecimento do delineamento do discurso político sobre a acessibilidade, nos planos nacional e internacional. Posteriormente, foram coletados dados estatísticos públicos, disponibilizados pelo Instituto Nacional de Estudos e Pesquisas Educacionais Anísio Teixeira (INEP), referentes às condições de acessibilidade nas escolas que compõem a rede pública de ensino de um município polo para as políticas de educação inclusiva, no estado de Mato Grosso do Sul. Por último, foram realizadas visitas nas escolas urbanas de Ensino Fundamental do município que receberam adequações arquitetônicas visando à acessibilidade. Esses espaços foram registrados com uma câmera fotográfica para posterior análise. Foram abordados aspectos relativos aos avanços sobre a constituição dos direitos das pessoas com deficiências, com a atenção voltada à materialização das condições de acessibilidade arquitetônica, nas instituições escolares, como uma forma de leitura do respeito a essas

\footnotetext{
${ }^{1}$ Este artigo teve como base a dissertação de mestrado Acessibilidade: uma análise da existência de barreiras à inclusão de alunos com deficiência/NEE na rede municipal de ensino de Corumbá, MS.
} 
http://dx.doi.org/10.5902/1984686X29387

pessoas na sociedade atual. Os resultados indicam que a rede municipal tem se organizado para cumprir as metas dos programas do governo federal no tocante à acessibilidade arquitetônica na escola. Porém, as alterações realizadas não garantem os fins propostos.

Palavras-chave: Acessibilidade; Direitos humanos; Educação inclusiva.

\section{ABSTRACT}

The enrolment of students with disabilities and mobility impairments in schools has triggered several changes, including the ones related to the organization of the school facilities. The paper aims to analyze the architectural accessibility to public school buildings, from the perspective of compliance with the fundamental rights such as the recognition as a person, the right to education, freedom of movement and personal safety, among others. The initial documentary research led to the identification of the political discourse around accessibility, both at national and international levels. Subsequently, public statistical data were collected from the National Institute for Educational Studies and Research "Anísio Teixeira" (INEP), regarding the accessibility conditions in the schools that make up the public school system in a municipality where inclusive education policies have been implemented, in the state of Mato Grosso do Sul. The investigation also included visits to urban elementary schools where architectural adjustments related to accessibility have taken place. Such adjustments were photographed for further analysis. The analyses addressed aspects related to advances in the constitution of the rights of people with disabilities, with a focus on the materialization of architectural accessibility conditions in the educational institutions as a way of respecting these people in current society. The results indicate that the municipal network has been organized to meet the objectives of the federal government programs concerning architectural accessibility to school buildings. However, not all changes ensure the proposed purposes.

Keywords: Accessibility; Human rights; Inclusive education.

\section{RESUMEN}

La presencia de alumnos con discapacidades y con dificultades de locomoción en las escuelas tiene promovido diversos cambios e, entre ellos, los relativos a la organización de los espacios. Este artículo tiene el objetivo de analizar la accesibilidad arquitectónica en escuelas públicas, bajo la perspectiva del cumplimiento de los derechos fundamentales, como el reconocimiento como persona, el recibimiento de instrucción/educación, la libertad de locomoción, seguranza personal, entre otros. Para el desarrollo de este trabajo, inicialmente, se realizó una investigación documental, que posibilitó conocer el delineamiento del discurso político sobre a accesibilidad, en el plan nacional e internacional. Posteriormente fueron colectados datos estadísticos públicos, disponibles en el Instituto Nacional de Estudos e Pesquisas Educacionais Anísio Teixeira (INEP), referentes a las condiciones de accesibilidad en escuelas que toman parte de la rede pública de enseñanza de una ciudad foco de políticas de educación inclusiva, en el estado de Mato Grosso do Sul. Por último, fueron realizadas visitas en escuelas urbanas de Enseñanza Fundamental, en esa ciudad, e que recibieron adecuaciones arquitectónicas, para posibilitar la accesibilidad. Esos espacios fueron registrados con la utilización de una cámara fotográfica 
http://dx.doi.org/10.5902/1984686X29387

para el posterior análisis. Fueron considerados aspectos relativos a los avances sobre la constitución de los derechos de las personas con discapacidades, con la atención a la materialización de condiciones de accesibilidad arquitectónica en las instituciones escolares como una forma de lectura del respecto a esas personas en la sociedad actual. Los resultados indican que las escuelas públicas tienen se organizado para cumplir las metas de los programas del gobierno federal relativos a la accesibilidad arquitectónica en las escuelas. Sin embargo, los cambios no garantizan los objetivos propuestos.

Palabras clave: Accesibilidad; Derechos humanos; Educación inclusiva.

\section{Introdução}

Dentre os direitos humanos, a educação escolar/instrução é uma prerrogativa fundamental de todo indivíduo. Além de assegurar a gratuidade e a obrigatoriedade, as nações devem reputar a educação como sustentáculo na construção de novas mentalidades (ONU, 1948). O processo educativo favorece a formação cultural do ser humano (PINO, 2005) e constrói "[...] direta e indiretamente em cada indivíduo singular a humanidade que é produzida histórica e coletivamente pelo conjunto dos homens" (SAVIANI 2008, p. 13). A realização desse ato, nas sociedades modernas, encontra na escola o espaço formal, por excelência.

Pela relação existente entre educação e desenvolvimento humano, a condição humana vem constantemente passando por ressignificações, tendo em vista a organização das diferentes sociedades, os conhecimentos disponíveis em cada momento histórico, os valores ético-culturais, religiosos, dentre outros fatores. Essas diferentes circunstâncias têm orientado formas de percepção de grupos minoritários, como é o caso da população com deficiência, que tem sido objeto de diversos olhares (MISÈS, 1977; PESSOTTI, 1984). A partir das múltiplas maneiras de se pensar o outro, consolidadas ao longo do desenvolvimento da humanidade, definiram-se os modos de constituição de direitos e deveres às pessoas em geral, e também de desmerecimento às que não se enquadraram nas convenções culturalmente estabelecidas.

A desconsideração de segmentos da população como pertencentes à condição humana foi uma constante até o final do século XVIII, quando mudanças significativas nas relações sociais levaram a alterações no entendimento sobre o ser humano. Para Rizzi et al. (2011, p. 14), esse período propiciou "[...] o surgimento de uma série de direitos civis, como o direito à vida, à liberdade de expressão, de pensamento, a garantia de que a lei só proibiria o que fosse prejudicial à sociedade, entre outros". Tais direitos são denominados civis e políticos, ou de primeira geração. 


\section{http://dx.doi.org/10.5902/1984686X29387}

O conhecimento dos aspectos históricos é fundamental para o entendimento de documentos como a Declaração dos Direitos do Homem e do Cidadão (Déclaration des Droits de l'Homme et du Citoyen), de 1789, pois a produção discursiva é construída em sua base material. Bakhtim (1992, p. 299) explicita que, no desvelar de um enunciado, percebese o "[...] intuito discursivo ou o querer-dizer do locutor que determina o todo do enunciado: sua amplitude, suas fronteiras". Assim, a constituição da produção discursiva compreende as contradições do seu momento histórico, delimitando a sua ação.

No século XIX, com o avanço do capitalismo industrial, acentuaram-se as desigualdades sociais (RIZZI et al., 2011), o que desencadeou, em países da Europa e em outros com industrialização em desenvolvimento, um processo de lutas por direitos sociais, culturais e econômicos, correspondendo aos direitos de segunda geração (idem).

A primeira metade do século $X X$ foi um período conturbado, com graves acontecimentos contra a vida nas duas grandes guerras, levando milhões de pessoas a hospitais, sanatórios e campos de concentração (REES, 2013). Especificamente, a segunda guerra evidenciou a ineficiência dos estados nacionais para a proteção dos direitos humanos até então adquiridos. Para tentar evitar o surgimento de mais ameaças à vida humana, foram instituídos novos imperativos legais, que caracterizaram a terceira geração, visando à proteção "[...] não somente a pessoa individual ou socialmente, mas também os direitos da humanidade, inclusive o direito das futuras gerações" (RIZZI et al., 2011, p. 14).

No preâmbulo da Declaração Universal dos Direitos Humanos (DUDH) de 1948 adverte-se que o "[...] desconhecimento e o desprezo dos direitos do homem conduziram a atos de barbárie", que consolidam a violência de forma natural e legítima. Como forma de construção de uma diferente mentalidade, dentre outras medidas de caráter nacional e internacional, o ensino e a educação deveriam/devem promover o respeito a esses direitos e liberdades. Essa assertiva sublinha a instrução/educação como um instrumento fundamental para a formação das novas gerações, pois viabiliza a construção, na própria humanidade, de uma segunda natureza. Dessa maneira, educar tendo em vista os direitos humanos é buscar soluções exequíveis para a

[...] formação de nova mentalidade coletiva para o exercício da solidariedade, do respeito às diversidades e da tolerância. Como processo sistemático e multidimensional que orienta a formação do sujeito de direitos, seu objetivo é combater o preconceito, a discriminação e a violência, promovendo a adoção de novos valores de liberdade, justiça e igualdade. (BRASIL, 2010, p. 185). 


\section{http://dx.doi.org/10.5902/1984686X29387}

A mentalidade que se busca deve ser construída cotidianamente nos espaços sociais, entre eles, nas escolas. Tendo em mente os diversos contextos relacionados ao tratamento negligente destinado às pessoas com deficiência, expressivamente registrado na literatura especializada (Pessotti, 1984; Jannuzzi, 2004), é imperativo promover e garantir a participação dessa população nas diferentes instituições sociais, especialmente nas atividades que envolvem a escolarização. A existência de diversas barreiras que obstruem, historicamente, a completa participação das pessoas com deficiências deve ser foco de atenção.

A leitura sobre o significado social das pessoas evidencia-se não apenas em discursos, mas também em outras condições materiais de vida. De acordo com Wilheim (1976), na análise dos aspectos do planejamento urbano, é crucial aprender a observar, pois a paisagem "[...] comunica informações a seu respeito, sendo, portanto, possível sua 'leitura'. Esta implica percepção" (p. 59). Existem conexões entre as relações pessoais e a organização dos espaços, de modo que "[...] os sistemas e subsistemas (atividades significativas) apoiam-se nas estruturas físicas disponíveis" (p. 66).

Este artigo propõe-se a levar esses aspectos em consideração, com o objetivo de analisar espaços escolares sob o olhar do respeito à participação das pessoas com deficiências e dificuldades de locomoção, como um direito humano fundamental. Para seu desenvolvimento, foram utilizados dados disponibilizados pelo Instituto Nacional de Estudos e Pesquisas Educacionais Anísio Teixeira (INEP) sobre as condições de acessibilidade arquitetônica de escolas urbanas de uma rede escolar de um município polo para as políticas de Educação Inclusiva no interior do Brasil. Também foram realizadas visitas in loco em todas as escolas da região urbana da rede pública municipal do mesmo município que ofertam o Ensino Fundamental, como uma forma de capturar informações sobre a condição dessas pessoas na sociedade atual. Nesses locais, os espaços foram registrados com o uso de câmara fotográfica, com a intenção de não apenas denunciar/alertar os problemas encontrados, mas também para "[...] sensibilizar os responsáveis administrativos para mudanças" (MANZINI, 2014, p. 142), a fim de desmontar barreiras atitudinais.

\section{A acessibilidade, uma reivindicação humana}

Quando se estabelece que todos os homens nascem livres, referindo-se ao artigo primeiro da Declaração Universal dos Direitos Humanos, percebe-se certo distanciamento 
entre o plano do discurso e a sua aplicabilidade material, uma vez que a concretização dessa liberdade é restrita a alguns momentos da história, com a insurreição dos processos de lutas deflagradas no seio da sociedade civil e do Estado (HUNT, 2009). A existência de tensões constantes em relação à efetivação dos direitos a diferentes populações evidencia que o estabelecimento da DUDH não é garantia de preservação das conquistas sociais, como ressaltam Cardoso e Viola (2014):

\begin{abstract}
Um marco fundamental para consolidar as aspirações pacifistas tanto no sentido de legitimar e confirmar os esforços de compreensão internacional, as declarações e os ordenamentos jurídicos nacionais e internacionais não bastam para garantir os direitos civis e políticos, preservar conquistas sociais e econômicas e, mesmo fortalecer as aspirações de dimensão coletiva como os da preservação do meio ambiente e da paz. Ao contrário, frutos das carências e da dor, os direitos humanos constituem-se como um campo de disputas entre setores sociais e entre a sociedade civil e o Estado (CARDOSO; VIOLA, 2014, p. 208).
\end{abstract}

Pensar a acessibilidade tendo como foco a participação plena de pessoas com deficiências, particularmente na área da educação, é fator fulcral para a consolidação dos ideais que orientam esse projeto social. A esse respeito, Nunes e Nunes Sobrinho (2008, p. 269) lembram que "[...] a acessibilidade se constitui em uma das mais antigas e legitimas reivindicações das pessoas com deficiência".

Registram Santos et al. (2005, p. 56) que "[...] em 1975 a ONU adotou a Declaração dos Direitos das Pessoas Portadoras de Deficiência que proclamou a igualdade de direitos civis e políticos para as pessoas portadoras de deficiência". Nesse mesmo ano, foram anunciadas, pela Organização Internacional de Padronização (International Organization for Standardization - ISO), as diretrizes a serem estabelecidas em edifícios, para atender a essa população. A partir daí, ocorreu ampla divulgação desses parâmetros, centrando-se no campo arquitetônico e logo expandindo-se. Os EUA se destacaram ao instituir a lei de reabilitação, em 1973, estipulando a criação de adaptações em ambientes para menor restrição a setores públicos relacionados ao trabalho e ao ensino superior. Essa medida foi ampliada, em 1975, ao ensino de crianças, jovens e adultos com a promulgação do "Education for All Handicapped Children Act" (USA, 1975) (MENDES, 2006; SILVA FILHO, 2017). Autores (FONSECA, 2004; MENDES, 2006) veem a legislação americana como um marco histórico, entendendo que o processo de inclusão de crianças com diferentes necessidades ao lado das demais que compõem o universo heterogêneo das salas regulares é um "[...] dos princípios basilares da sociedade democrática e solidária" (FONSECA, 2004, p. 49), evidenciado com o Education for Handicapped Children Act. 


\section{Ampliação das discussões no plano internacional e a legislação brasileira}

Os anos 1980 foram marcados, em vários países, inclusive no Brasil, por grande participação da sociedade civil na organização da política de Estado (NEVES, 2005). Nesse período, a ONU fomentou mais discussões sobre a participação social, disseminando o princípio da igualdade de oportunidades.

Em relação aos direitos das pessoas, 1981 foi instituído como o Ano Internacional da Pessoa com Deficiência. No ano seguinte, a Assembleia Geral da ONU lançou o Programa de Ação Mundial para as Pessoas com Deficiência, com o propósito de impulsionar o seu direito de desfrutar, em condições de igualdade, da qualidade de vida oriunda do desenvolvimento econômico e social, posto que suas desvantagens ${ }^{2}$ poderiam a ser acentuadas em função da sua relação com o meio.

Em 1983, a Organização Internacional do Trabalho (OIT) aprovou a Convenção 159 sobre Reabilitação Profissional em Emprego de Pessoas Portadoras de Deficiência, mesmo ano em que foi definida a década das Nações Unidas para as Pessoas com Deficiência.

Dez anos mais tarde, a ONU admitiu a premência da intensificação de ações para promover os Direitos Humanos à população com deficiência e sua efetiva participação social. O documento Normas Sobre a Igualdade de Oportunidades para as Pessoas com Deficiência (ONU, 1993) legitimou a acessibilidade como requisito para a igualdade de participação das pessoas, cujo significado vital deveria ser reconhecido por parte dos estados-membros. Empenhados com essa questão, os países deveriam adotar medidas, por meio de programas de ação, para viabilizar a acessibilidade ao meio físico e adotar medidas para garantir o acesso à informação e à comunicação. Dentre as Áreas fundamentais para a igualdade de participação, encontra-se a educação.

No Brasil, com a Constituição Federal de 1988, assegura-se a participação da sociedade civil nas decisões públicas, com a existência de vários conselhos e conferências

\footnotetext{
2 O termo desvantagem foi apresentado pela primeira vez no documento: Regras Gerais sobre a Igualdade de Oportunidades para Pessoas com Deficiências, especificando que "desvantagem" (handicap) significa a perda ou a limitação das possibilidades de tomar parte da vida da comunidade em condições de igualdade em relação aos demais cidadãos. Essa palavra descreve a situação da pessoa com deficiência em relação ao seu meio. O objetivo do conceito consiste em realçar os defeitos de concepção do meio físico envolvente e de muitas das atividades organizadas no seio da sociedade, tais como, por exemplo, a informação, a comunicação e a educação, que impedem as pessoas com deficiências de delas participar em condições de igualdade (ONU, 1993).
} 


\section{http://dx.doi.org/10.5902/1984686X29387}

de participação social nas instâncias municipal, estadual e federal. Desde então, o país vem elaborando medidas e normas para o cumprimento de compromissos externos e internos relativos aos direitos das pessoas com deficiências.

Em 1994, um dos princípios orientadores do Marco de Ações sobre Necessidades Educativas Especiais que acompanha a Declaração de Salamanca foi: "[...] las escuelas deben acoger a todos los niños, independientemente de sus condiciones físicas, intelectuales, sociales, emocionales lingüísticas u otras" (UNESCO, 1994, p. 6). Alertou-se para o fato de que "[...] las escuelas ordinarias con esta orientación integradora representan el media más eficaz para combatir las actitudes discriminatorias, crear comunidades de acogida, construir una sociedad integradora y lograr la educación para todos". (p. ix). Esses documentos, oriundos da Conferência Mundial Sobre Necessidades Educativas Especiais: Acesso e Qualidade, realizada em Salamaca em 1994, impactaram fortemente os rumos adotados por diferentes países em relação à organização das escolas. O Brasil tem se fundamentado nessa documentação para as ações destinadas à construção de uma educação inclusiva (BRASIL, 2008).

Mais de dez anos após a divulgação desse material, foi realizada a Convenção Internacional Sobre os Direitos das Pessoas com Deficiência - CDPCD (BRASIL, 2009) ${ }^{3}$, ratificada no Brasil por meio dos decretos № 186/2008 e № 6.949/2009. O documento oriundo desse encontro alerta para o fato de que, mesmo com o arcabouço legal existente, "[...] as pessoas com deficiência continuam a enfrentar barreiras contra sua participação como membros iguais da sociedade e violações de seus Direitos Humanos em diversas partes do mundo", e reconhece, dentre outros aspectos, a posição de destaque da acessibilidade para a participação de todos em igualdade de condições. Conforme anunciou a então Ministra de Estado Chefe da Secretaria de Direitos Humanos da Presidência da República, Maria do Rosário Nunes, em texto de apresentação da CDPCD no país, "[...] a Convenção e seu Protocolo Facultativo são uma referência essencial para o País que queremos e já começamos a construir: um Brasil com acessibilidade, no sentido mais amplo desse conceito" (p. 9). Disse ainda a Ministra que é essencial assegurar que os "[...] espaços, serviços e produtos - como componentes da democracia - são para todas e todos" (BRASIL, 2013, p. 11).

\footnotetext{
${ }^{3}$ A sigla CDPCD será utilizada no decorrer do texto.
} 
http://dx.doi.org/10.5902/1984686X29387

No art. IX, a CDPCD anuncia que os Estados-Partes desenvolverão ações para assegurar

[...] às pessoas com deficiência o acesso, em igualdade de
oportunidades com as demais pessoas, ao meio físico, ao transporte,
à informação e comunicação, inclusive aos sistemas e tecnologias da
informação e comunicação, bem como a outros serviços e instalações
abertos ao público ou de uso público, tanto na zona urbana como na
rural (Artigo 9).

A concepção de acessibilidade assumida nessa Convenção supera a ideia de adequações arquitetônicas (posicionamento que pode provocar a redução e a limitação do alcance desse conceito) e fomenta um amplo debate político, pois inscreve outros aspectos que envolvem condições indispensáveis à participação social em igualdade de oportunidades. Quanto ao acesso à educação, o artigo 24 da CDPCD estabelece que "[...] Para efetivar esse direito sem discriminação e com base na igualdade de oportunidades, os Estados Partes assegurarão sistema educacional inclusivo em todos os níveis" (Artigo 24).

Atualmente, as normas relativas à acessibilidade ampliam a sua definição, ultrapassando o foco apenas nas barreiras físicas/arquitetônicas. A lei 10.098 de 2000 apresenta como fatores impeditivos (barreiras) "[...] qualquer entrave ou obstáculo que limite ou impeça o acesso, a liberdade de movimento e a circulação com segurança das pessoas" (BRASIL, 2000b), com quatro subdivisões: arquitetônicas urbanísticas; arquitetônicas na edificação; arquitetônicas nos transportes; e nas comunicações, que seriam as relacionadas a "[...] qualquer entrave ou obstáculo que dificulte ou impossibilite a expressão ou o recebimento de mensagens por intermédio dos meios ou sistemas de comunicação, sejam ou não de massa" (idem). O decreto 5.296 de 2004, que regulamenta essa lei e a Lei 10.048/2000, acrescenta ao conceito de acessibilidade os vocábulos "total e assistida", de modo a associar a noção de que o usuário, mesmo possuindo recursos disponíveis à sua independência e participação, pode necessitar do auxílio de um mediador.

Recentemente, foram elencados "[...] critérios e parâmetros técnicos a serem observados quanto ao projeto, construção, instalação e adaptação do meio urbano e rural, e de edificações às condições de acessibilidade" (ABNT, 2015), pelo Comitê Brasileiro de Acessibilidade, a fim de subsidiar operadores e usuários de bens e serviços público/privado. A Comissão de Estudo de Acessibilidade em Edificações, na NBR9050/2015, assume acessibilidade como a 
http://dx.doi.org/10.5902/1984686X29387

[...] possibilidade e condição de alcance, percepção e entendimento para utilização, com segurança e autonomia, de espaços, mobiliários, equipamentos urbanos, edificações, transportes, informação e comunicação, inclusive seus sistemas e tecnologias, bem como outros serviços e instalações abertos ao público, de uso público ou privado de uso coletivo, tanto na zona urbana como na rural, por pessoa com deficiência ou mobilidade reduzida (ABNT, 2015, p. 2,).

A definição de acessibilidade da Associação Brasileira de Normas Técnicas (ABNT) assemelha-se à adotada pela Lei Federal $n^{\circ}$ 13.146, Lei Brasileira de Inclusão da Pessoa com Deficiência, também denominada de Estatuto da Pessoa com Deficiência (BRASIL, 2015), por trazer outros aspectos substantivos para a efetivação da participação plena das pessoas com deficiência ou mobilidade reduzida. As barreiras são assim classificadas:
a) barreiras urbanísticas: as existentes nas vias e nos espaços públicos e privados abertos ao público ou de uso coletivo;
b) barreiras arquitetônicas: as existentes nos edifícios públicos e privados;
c) barreiras nos transportes: as existentes nos sistemas e meios de transportes;
d) barreiras nas comunicações e na informação: qualquer entrave, obstáculo, atitude ou comportamento que dificulte ou impossibilite a expressão ou o recebimento de mensagens e de informações por intermédio de sistemas de comunicação e de tecnologia da informação; e) barreiras atitudinais: atitudes ou comportamentos que impeçam ou prejudiquem a participação social da pessoa com deficiência em igualdade de condições e oportunidades com as demais pessoas;
f) barreiras tecnológicas: as que dificultam ou impedem o acesso da pessoa com deficiência às tecnologias (idem)

A partir desse entendimento ancorado constitucionalmente, foram sendo demarcados novos rumos à consolidação da política nacional de educação sob os pressupostos da inclusão. Esses marcos legais garantem ao país um patamar de reconhecimento jurídico de direitos às pessoas com deficiências. No entanto, para que a participação dessa população não ocorra apenas em um plano procedimental, as mudanças jurídicas devem impactar a estrutura social, com alterações significativas em vários aspectos da organização da sociedade. Para isso, o Estado brasileiro tem implantado um conjunto de programas sociais. De modo especial, destacam-se os referentes à educação, com o objetivo de formar um sistema educacional inclusivo, que se propõe a garantir o acesso e a permanência de alunos com deficiências nas escolas de todo o país. Dentre os programas, ressalta-se o Programa Escola Acessível (PEA). 


\section{O PEA e a sua implantação em um município-polo}

O Programa Escola Acessível, originado em 2007, é uma ação do Ministério da Educação (MEC), através da articulação entre a Secretaria de Educação Continuada, Alfabetização, Diversidade e Inclusão (SECADI), o Fundo Nacional de Desenvolvimento da Educação (FNDE), as Secretarias de Educação e as escolas. Foi incorporado como uma das ações que integraram o Plano Nacional dos Direitos da Pessoa com Deficiência, Viver sem Limite, criado em 2011, cuja meta vislumbrava o atendimento de 42.000 escolas até 2014. O governo federal, representado pelo MEC/SECADI, no texto de apresentação do manual do PEA, informa:

O Programa Escola Acessível constitui uma medida estruturante para a consolidação de um sistema educacional inclusivo, concorrendo para a efetivação da meta de inclusão plena, condição indispensável para uma educação de qualidade (BRASIL, 2011, p. 7).

Pretendendo alcançar a meta de inclusão plena, o Estado brasileiro ressalta a importância desse programa como medida estruturante, com o seguinte objetivo geral:

Promover a acessibilidade e inclusão de alunos com deficiência,
transtornos globais do desenvolvimento e altas
habilidades/superdotação matriculados em classes comuns do ensino
regular, assegurando-lhes o direito de compartilharem os espaços
comuns de aprendizagem, por meio da acessibilidade ao ambiente
físico, aos recursos didáticos e pedagógicos e as comunicações e
informações (BRASIL, 2011, p. 6).

Quanto à execução do programa nas escolas, os sistemas de ensino deveriam se orientar pelo desenho universal, a fim de cumprir as normas de acessibilidade previstas pela ABNT/NBR9050/2004, pelo decreto 6.949/2009 e pelo Manual de Acessibilidade Espacial para Escolas: o direito à escola acessível. Os recursos para as obras estruturais foram disponibilizados às escolas selecionadas por meio do Programa Dinheiro Direto na Escola (PDDE).

O município estudado foi beneficiado pelo PEA, desde 2007, e mobilizou recursos próprios para adaptações em escolas que não foram atendidas por esse programa. Dados coletados no Censo Escolar (2015) facultam ao governo federal a construção do indicador social "acessibilidade". A Tabela 1 registra as adequações realizadas na rede municipal, a partir desse banco de dados. 


\section{http://dx.doi.org/10.5902/1984686X29387}

Tabela 1: Número de banheiros, dependências e vias adequadas às pessoas com deficiências (2007-2015) na totalidade da rede municipal.

\begin{tabular}{|l|c|c|c|c|c|c|c|c|c|}
\hline Ano & $\mathbf{2 0 0 7}$ & $\mathbf{2 0 0 8}$ & $\mathbf{2 0 0 9}$ & $\mathbf{2 0 1 0}$ & $\mathbf{2 0 1 1}$ & $\mathbf{2 0 1 2}$ & $\mathbf{2 0 1 3}$ & $\mathbf{2 0 1 4}$ & $\mathbf{2 0 1 5}$ \\
\hline $\begin{array}{l}\text { Banheiros } \\
\text { acessíveis }\end{array}$ & 5 & $*$ & 8 & 9 & 12 & 12 & 14 & 15 & 17 \\
\hline $\begin{array}{l}\text { Dependências e } \\
\text { vias adequadas }\end{array}$ & 4 & $*$ & 5 & 7 & 9 & 10 & 11 & 11 & 12 \\
\hline $\begin{array}{l}\text { Quantitativo de } \\
\text { escolas por ano }\end{array}$ & $\mathbf{2 7}$ & $\mathbf{2 7}$ & $\mathbf{2 7}$ & $\mathbf{2 7}$ & $\mathbf{2 8}$ & $\mathbf{2 8}$ & $\mathbf{2 8}$ & $\mathbf{3 4}$ & $\mathbf{3 5}$ \\
\hline
\end{tabular}

Fonte: Elaboração própria com base nos microdados do censo Escolar (2015). Nota: *Não foi possível acessar os dados neste ano.

A tabela exibe o crescimento do número de adaptações nas escolas no decorrer dos anos. No total, 17 escolas foram modificadas no período, 11 das quais receberam recursos do PEA e as outras da própria prefeitura. Uma leitura possível dos dados induz à identificação de uma mudança paulatina de mentalidade em relação aos direitos da pessoa com deficiência, pela preocupação com os aspectos de adequação arquitetônica como uma forma de acessibilidade.

No entanto, o contato in loco com 16 das 17 escolas $^{4}$ que sofreram modificações leva a outra leitura. Juntamente com a percepção das modificações, observou-se um conjunto de espaços fora dos padrões propostos pelas normas técnicas que, em grande parte dos casos, inviabiliza completamente o seu uso.

Figura 1 - Banheiro com dimensões e lavatório posicionados de modo inadequado para alunos usuários de cadeira de rodas.

Fonte: Elaboração própria (2016)

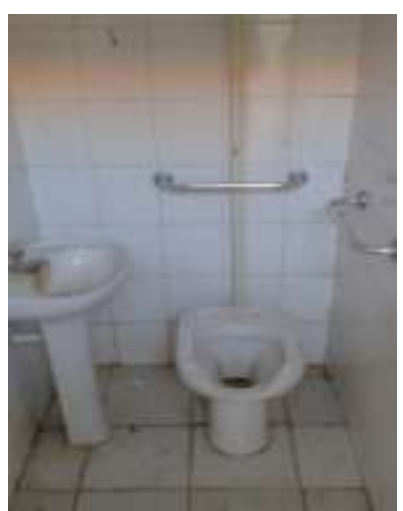

A fotografia mostra que o posicionamento do lavatório impossibilita o desenvolvimento de formas de transferências dos usuários de cadeiras de rodas. A construção não obedeceu à orientação de que "[...] deve ser instalado lavatório sem coluna ou com coluna suspensa ou lavatório sobre tampo, dentro do sanitário ou boxe acessível, em local que não interfira

\footnotetext{
${ }^{4}$ Das 17 escolas da municipal de ensino que ofertavam o ensino fundamental e que receberam obras de adaptações, foram visitadas 16. Apenas uma unidade não foi visitada por localizar-se em um distrito distante da zona urbana do município estudado.
} 
http://dx.doi.org/10.5902/1984686X29387

na área de transferência para a bacia sanitária" (ABNT, 2015, p. 85). Além dos problemas relacionados à organização deste espaço, a falta de higiene no local denuncia seu abandono e/ou inutilização. Logo, é preciso considerar que a existência de uma dependência nessas condições, e classificada como acessível às pessoas com deficiência, pode comprovar falta de conhecimento das normas técnicas, negligência ou apontar para a ocorrência da barreira atitudinal que, além de contribuir para a invisibilidade e exclusão de muitos sujeitos, pode vir a ocasionar inexistência e/ou precariedade das condições de acessibilidade em diversos espaços escolares.

Verificou-se também que em algumas escolas não havia portas com aberturas adequadas nos banheiros. A ABNT (2015) orienta que se "a porta instalada for do tipo de eixo vertical, deve abrir para o lado externo do sanitário ou boxe e possuir um puxador horizontal no lado interno do ambiente" (p. 85). Das escolas que sofreram obras nos banheiros, nenhuma possuía puxadores horizontais instalados na parte interna desses locais. Em alguns casos, não existiam portas ou maçanetas externas e/ou internas, configurando o desrespeito e a violação da dignidade dos estudantes e demais usuários destes ambientes. Nas imagens a seguir, é possível observar, da esquerda para a direita, o sentido da abertura das portas, a ausência de maçanetas e da própria porta (imagem 4).

Figura 2 - Abertura de portas de banheiros acessíveis
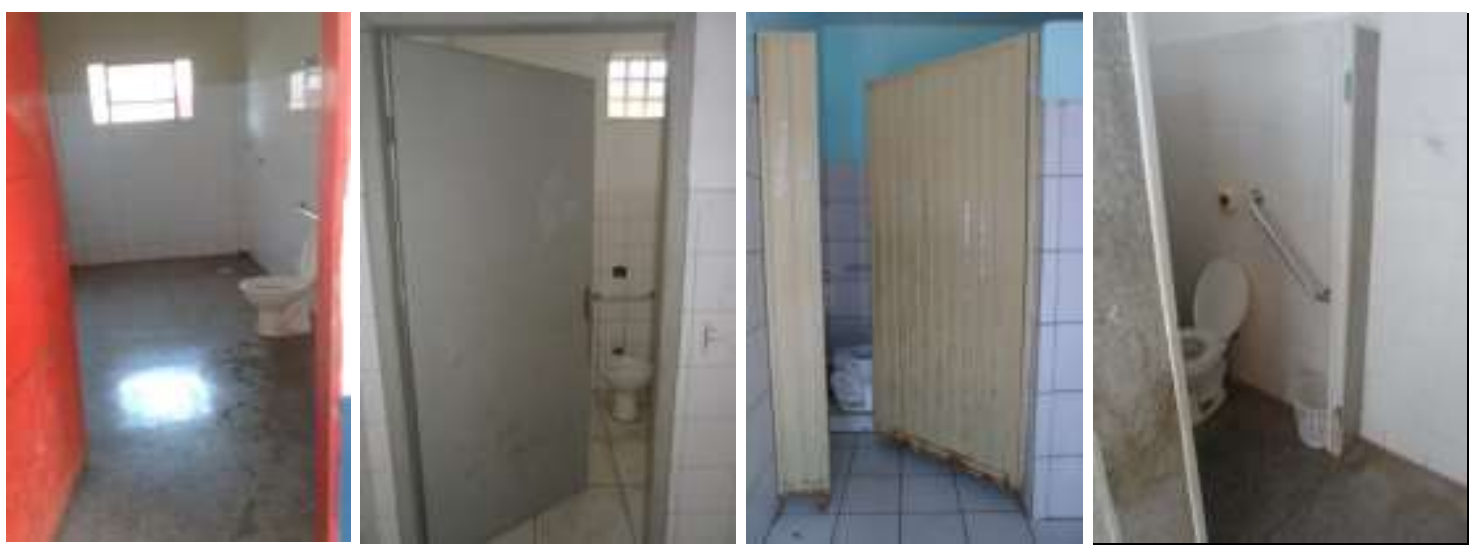

Fonte: Elaboração própria (2016)

Além de não adequados, muitos banheiros encontravam-se sem qualquer condição de uso, servindo de espaço para depósitos, como se constata nas seguintes fotos: 
Figura 3 - Banheiros sem condições de uso

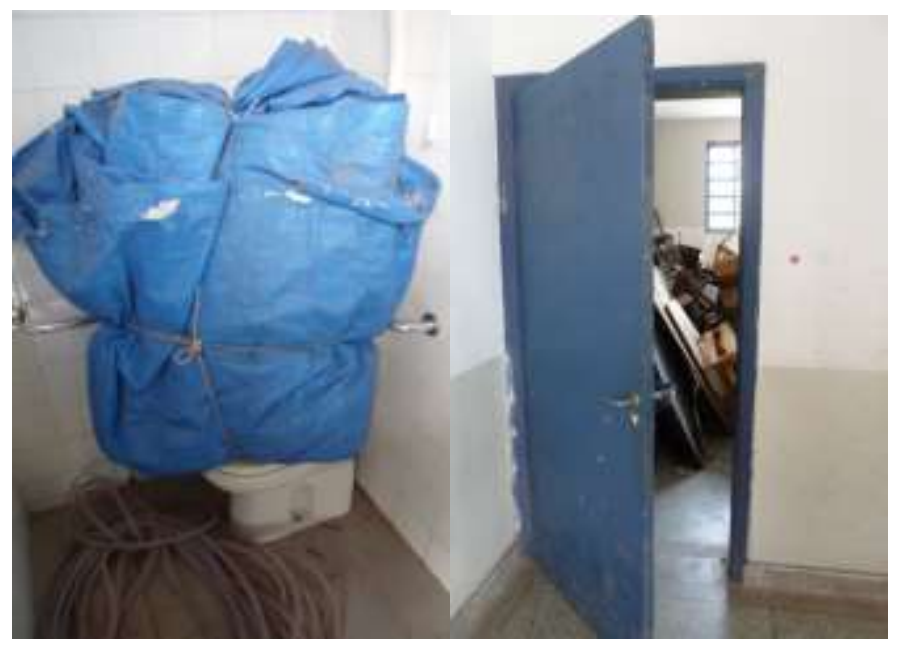

Fonte: Elaboração própria (2016)

As imagens acima evidenciam a materialidade dos espaços compartilhados por pessoas, em diferentes escolas, em um determinado município. Não se trata de montagens artificiais, mas de edificações em que, diariamente, centenas de pessoas passam várias horas de seus dias. Como espaços, são possíveis leituras, como explica Wilheim (1976). Se existem conexões entre as relações pessoais e a (des)organização dos espaços, tais imagens podem denotar desprezo às pessoas que transitam por esses locais e, de modo mais direto, às que têm deficiências ou mobilidade reduzida.

As imagens dos locais que sofreram adaptações contradizem os dados registrados e contabilizados no INEP. Assim, em relação à concretização da política de inclusão educacional, a comparação entre os dois tipos de dados, o numérico e as imagens, remete a trabalhos que denunciam que incluir não significa apenas garantir a matrícula dos alunos (MUÑUZ, 2008; CARVALHO, 2013). No entanto, se a avaliação da política de educação inclusiva baseia-se nas informações numéricas, a rede municipal dessa localidade pode ser considerada como em pleno movimento para o cumprimento do objetivo de construção de um sistema educacional inclusivo.

\section{Considerações Finais}

Trabalhos como os de Balbinot; Hauber (2017), desenvolvido a partir de análise de dados de matrículas de alunos da educação especial, registram que "a educação não está inerte, mas sim, sensível às questões da educação especial e aperfeiçoando-se para 


\section{http://dx.doi.org/10.5902/1984686X29387}

atender as demandas dos sujeitos com necessidades educacionais especiais" (p. 672). Juntamente ao aumento do número de matrículas em escolas comuns há, também, o aumento da legislação que trata de questões de acessibilidade para pessoas com deficiências (GUERREIRO, 2012). Esses aspectos indicam que o país registra avanços em relação à garantia de acesso à escola. Nesse sentido, este estudo também identificou avanços sobre os direitos das pessoas com deficiências.

Não ignorando essas mudanças, o contato com as condições de acessibilidade arquitetônica de escolas que passaram por adequações de espaços, com recursos públicos de projetos ou programas de atenção à população com deficiências em um município brasileiro evidencia que estar na escola não basta; as imagens apresentadas atestam isso. O conceito de acessibilidade está diretamente relacionado ao cotidiano dos alunos (MANZINI, 2008). Sem esse requisito, muitos não têm as mesmas oportunidades constitucionalmente definidas. A adaptação/adequação do ambiente escolar envolve um processo sistêmico que inclui diversos setores interligados ao desenvolvimento da política de educação sob a perspectiva da inclusão. Conforme atesta a própria CDPCD, é necessário transpor uma série de barreiras que foram se amalgamando, historicamente, na sociedade.

Para Jannuzzi (2004), retomar o passado pode proporcionar melhor compreensão da realidade, com vistas a evidenciar velhos modos e modelos que ainda persistem e vislumbrar a construção de novos caminhos. Pensar novas práticas e novas atitudes para o bem do outro demanda olhar nossa história e reconhecer barreiras evidentes ou não, explícitas ou implícitas. Essa forma de olhar favorece a desconstrução das barreiras (físicas ou não) que limitam as capacidades de muitos alunos.

A desqualificação dos espaços indica a desconsideração com a população e com a educação oferecida a ela. O oferecimento da educação com qualidade é dever do Estado (BRASIL, 2015); o acesso a esse direito social e fundamental a toda pessoa requer a organização dos espaços. A falta de acessibilidade arquitetônica no ecossistema educacional é uma violação aos Direitos Humanos Fundamentais e um fator negativo à consolidação dos ideais da DUDH (1948), legitimados constitucionalmente e inscritos no Programa Nacional de Direitos Humanos. Tal Programa, implementado no país desde 1996, trouxe, em sua última revisão, em 2010, a definição de acessibilidade como um instrumento para a garantia de igualdade na diversidade às pessoas com deficiência. 


\section{http://dx.doi.org/10.5902/1984686X29387}

As imagens constantes deste trabalho provocam uma leitura do significado do outro no espaço escolar: alguém invisível, apesar de presente; destituído de seus direitos, apesar de tê-los legalmente garantidos. A inadequação dos espaços não representa apenas uma barreira arquitetônica. É, sobretudo uma barreira atitudinal, que insiste em fazer-se manifesta, inclusive corroendo o que, pouco a pouco, vem sendo construído. Além do desrespeito aos alunos e profissionais com deficiências que estão nas escolas, presenciase o desrespeito aos recursos públicos, inutilizados ou utilizados irresponsavelmente.

\section{Referências}

ABNT. NBR 9050/2015: Acessibilidade a edificações, mobiliário, espaços e equipamentos urbanos. DISPONÍVEL EM http://www.abnt.org.br/normalizacao. Acessado em 06/06/2016.

\section{BAKHTIN, M.M. Estética da criação verbal. São Paulo: Martins Fontes, 1992.}

BALBINOT, Alexandre Dido; HAUBER, Arieli. Análise de matrículas como indicadores da evolução da educação especial no estado do Rio De Janeiro. Revista. Eletrônica Pesquiseduca,v. 09, n. 19, p. 663--673, set.-dez. 2017. Disponível em: http://periodicos.unisantos.br/index.php/pesquiseduca/article/download/560/pdf. Acesso em agosto de 2018.

BRASIL. Decreto 7.612 de 17 de novembro de 2011. Institui o Plano Nacional dos Direitos da Pessoa com Deficiência - Plano Viver sem Limite. Brasília, 2011. Acessado em 15/07/2016. Disponível em: http://www.planalto.gov.br/ccivil_03/_Ato20112014/2011/Decreto/D7612.htm.

BRASIL. Decreto no 6.949, de 25 de agosto de 2009. Promulga a Convenção Internacional sobre os Direitos das Pessoas com Deficiência e seu Protocolo Facultativo, assinados em Nova York, em 30 de março de 2007. Disponível em: http://www.planalto.gov.br/ccivil_03/_ato2007-2010/2009/decreto/d6949.htm

BRASIL. Lei 10.048/00. Dá prioridade de atendimento às pessoas que especifica, e dá outras providências. Brasília, 2000a. Disponível em: http://www.planalto.gov.br/Ccivil_03/LEIS/L10048.htm

BRASIL. Lei 10.098/00. Estabelece normas gerais e critérios básicos para a promoção da acessibilidade das pessoas portadoras de deficiência ou com mobilidade reduzida, e dá outras providências, Brasília, 2000b. Disponível em: http://www.planalto.gov.br/ccivil_03/LEIS/L10098.htm

BRASIL. Lei 13.146/15. Institui a Lei Brasileira de Inclusão da Pessoa com Deficiência (Estatuto da Pessoa com Deficiência). http://www.planalto.gov.br/ccivil_03/_Ato20152018/2015/Lei/L13146.htm 
BRASIL. Ministério da Educação/Secretaria de Educação Continuada, Alfabetização, Diversidade e Inclusão. Documento Orientador do Programa Escola Acessível. Brasília, 2013.

BRASIL. Política Nacional de Educação Especial na perspectiva da Educação Inclusiva. Documento elaborado pelo Grupo de Trabalho nomeado pela Portaria no 555/2007, prorrogada pela Portaria no 948/2007, entregue ao Ministro da Educação em 07 de janeiro de 2008. Disponível em: http://portal.mec.gov.br/arquivos/pdf/politicaeducespecial.pdf

BRASIL. SEDH. Presidência da República. Programa Nacional de Direitos Humanos (PNDH-3). Brasília: SEDH/ PR, 2010.

CARDOSO, M.A.; VIOLA, S.E.A. Complementariedade entre a educação em direitos humanos e a educação para a paz. IN: Brabo, T.S.A.M., Direitos humanos, educação e participação popular: 50 anos do Golpe Militar, Marília: Oficina Universitária, São Paulo, cultura acadêmica, 2014.

CARVALHO, M.F. O aluno com deficiência intelectual na escola: ensino, aprendizagem e desenvolvimento humano. In Meletti, S. M. F.; Kassar, M.C.M. (Org.). Escolarização de Alunos com Deficiências - Desafios e Possibilidades. Campinas, SP: Mercado de Letras, 2013. FONSECA, V. Tendências futuras da educação inclusiva. IN: CLAUS, D.S.; MOSQUEIRA, J.J.M. (Org.). Educação Especial: em direção à educação inclusiva. 2. ed. Porto Alegre: EDIPUCRS, 2004.

GUERREIRO, E.M.B.R. A acessibilidade e a educação: um direito constitucional como base para um direito social da pessoa com deficiência. Revista. Educação Especial, Santa Maria, v. 25, n. 43, p. 217-232, maio/ago. 2012.

HUNT, L. A invenção dos direitos humanos. Editora Companhia das Letras, 2009.

JANNUZZI, G.M. A educação do deficiente no Brasil: dos primórdios ao início do século XXI. Campinas: Autores Associados, 2004, 243p. (Col. Educação Contemporânea).

MANZINI, E. J. Uso do Registro Fotográfico em Pesquisa sobre Acessibilidade: Análise Histórica e Documental. In: Manzini, E.J.; Corrêa, P.M. (Org.). Avaliação de acessibilidade na educação infantil e no ensino superior. São Carlos: ABPEE/Marquezine \& Manzini editora, 2014, v. 1, p. 123-144.

MANZINI, E.J. Acessibilidade: Um aporte na legislação para o aprofundamento do tema na área de educação (281-290). In: Baptista, Cláudio Roberto et al. Educação especial: dialogo e pluralidade, Porto Alegre, Mediação, 2008.

MENDES, E.G. A radicalização do debate sobre inclusão escolar no Brasil. Rev. Bras. Educ., Rio de Janeiro, v. 11, n. 33, p. 387-405, Dec. 2006. Disponível em $<$ http://www.scielo.br/scielo.php?script=sci_arttext\&pid=S1413-

$24782006000300002 \& \operatorname{lng}=$ en\&nrm=iso>. Accesso em 08 Sept. 2017. http://dx.doi.org/10.1590/S1413-24782006000300002 


\section{http://dx.doi.org/10.5902/1984686X29387}

MISÉS, R. A criança deficiente mental - uma abordagem dinâmica. Rio de Janeiro: Zahar, 1977.

MUÑOZ, X.D. Representaciones y actitudes del profesorado frente a la integración de Niños/as con Necesidades Educativas Especiales al aula común. Revista Latinoamericana de Educación Inclusiva. Disponível em http://www.repositoriocdpd.net:8080/bitstream/handle/123456789/78/Art_DammMun ozX_RepresentacionesActitudesProfesorado_2008.pdf?sequence=1

NEVES, L.M.W. (Org.). A Nova Pedagogia da Hegemonia: Estratégias do capital para educar o consenso. São Paulo: Xamã, 2005. 312p.

NUNES, LROP; NUNES SOBRINHO, F. Acessibilidade. Educação especial: diálogo e pluralidade. Porto Alegre: Ed. Mediação, p. 269-279, 2008.

ONU. (1948). Carta Internacional de los derechos del hombre. 183a sesión plenaria. Disponible en http://www.un.org/ga/search/view_doc.asp?symbol=A/RES/217(III)\&referer=/english/ \&Lang $=S$

ONU. Normas sobre a Igualdade de Oportunidades para as Pessoas com Deficiência. Assembléia Geral da Organização das Nações Unidas em 20 de dezembro de 1993. Disponível em http://www2.camara.leg.br/atividadelegislativa/comissoes/comissoes-permanentes/cdhm/comite-brasileiro-de-direitoshumanos-e-politica-externa/RegGerlguaOportPesDef.html. Acesso em julho de 2017.

PESSOTTI, I. Deficiência mental: da superstição à ciência. São Paulo: EDUSP, 1984. 204p.

PINO, A. S. As marcas do humano. Às origens da constituição cultural da criança na perspectiva de Lev S. Vigotski. São Paulo: Cortez, 2005.

REES, L. O carisma de Adolf Hitler: o homem que conduziu milhões ao abismo. Rio de Janeiro, Leya, 2013.

RIZZI, Ester et al. Direito humano à educação. Plataforma Dhesca Brasil e Ação Educativa, Coleção Manual de Direitos Humanos - volume 07 Direito Humano à Educação - 2a edição - Atualizada e Revisada. Novembro 2011.

SANTOS, Aguinaldo et al. Acessibilidade de habitações de interesse social ao cadeirante. Um estudo de caso. Ambiente construído. Porto Alegre, V. 5, n. 1. P. 5575, 2005.

SAVIANI, D. Pedagogia histórico-crítica: primeiras aproximações. 10. ed. rev. Campinas: Autores Associados, 2008, 137p.

SILVA FILHO, D.M. Acessibilidade: Uma Análise da Existência de Barreiras à Inclusão de Alunos com Deficiência/NEE na Rede Municipal de Ensino de Corumbá, MS. Dissertação de Mestrado. Corumbá, Mato Grosso do Sul. 2017. 
UNESCO. Declaración de Salamanca de principios, políticas y práctica para las necesidades educativas especiales. Marco de acción sobre las necesidades especiales. Salamanca, España, 7-10 de junio de 1994.

WILHEIM, J. O substantivo e o adjetivo. São Paulo: Perspectiva, 1979.

\section{Correspondência}

Daniel Mendes da Silva Filho - Universidade Federal do Mato Grosso do Sul Campus do Pantanal, Programa de Pós-graduação em Educação, Unidade III, Rua Domingos Sahib, 99, Caixa Postal 252, CEP: 79.300-130, Corumbá, Mato Grosso do Sul, Brasil.

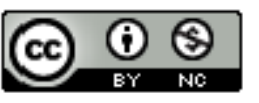

This work is licensed under a Creative Commons Attribution-NonCommercial 4.0 International (CC BY-NC 4.0) 